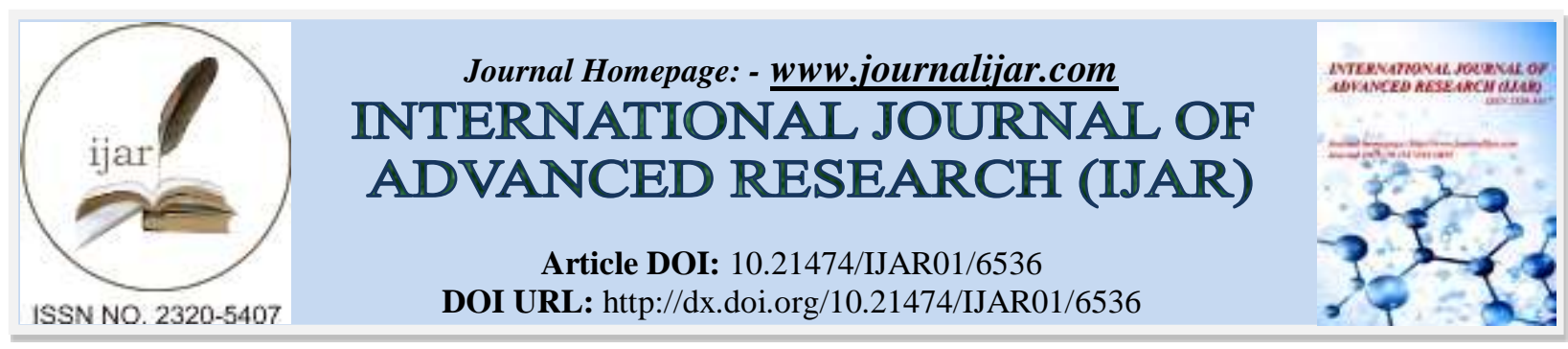

RESEARCH ARTICLE

\title{
ATYPICAL VITREOUS BRIDLE.
}

Souhaib Aboutoufayl, * Jihane Hakam, Ibtissam Hajji and Abdeljalil El Moutaouakil. Department of Ophtalmology, Mohammed VI University Hospital, Marrakech, Morocco.

\section{Manuscript Info}

Manuscript History

Received: 14 December 2017

Final Accepted: 16 January 2018

Published: February 2018
Abstract

Vitreous loss can be one of the most disconcerting complications of cataract surgery. It has been associated with a number of anterior and posterior segment complications. We report a case of an atypical aspect of vitreous bridle into the anterior chamber after cataract surgery.

Copy Right, IJAR, 2018,. All rights reserved.

\section{Case report:-}

Capsular rupture with vitreous loss is a daunting complication of cataract surgery, exposing to risk of retinal detachment and macular edema, which is associated with a poor visual outcome [1].

We report a case of an atypical aspect of vitreous bridle into the anterior chamber after cataract surgery.

A patient of 50 years underwent cataract surgery in April 2017 according to the technique of phacoemulsification and implantation in the sulcus. The surgery was complicated by vitreous loss during the procedure, which resulted in a significant decrease in visual acuity.

The ophthalmological examination showed the existence of a vitreous bridle incarcerated in the corneal scar, stretched in the anterior chamber and spread out like a comet's tail in the anterior vitreous with a dislocated lens (figure A and B). The examination of the fundus of the eye was strictly normal.

Although vitreous loss in cataract surgery is associated with sight threatening complications, including cystoid macular oedema and retinal detachment, the outcomes can be good [2].

Prevention of vitreous loss, whenever possible, remains important. Good practice includes preoperative identification of patients with a high risk of such a complication, so that this can influence the type of cataract surgery and choice of surgeon [1].

When vitreous loss occurs, there is a risk that inappropriate immediate management can have a devastating outcome for the patient, particularly, in the case of posteriorly dislocated lens fragments. Those eyes have a high rate of retinal detachment and an experienced posterior segment surgeon should be involved at a very early stage in their management $[3,4]$.

\section{Conflicts of interest:-}

All the authors declare to have no conflict of interest. 


\section{Figures}

Figure A: Vitreous bridle incarcerated in the corneal scar

Figure B: extension in the anterior chamber like a comet's tail with a dislocated lens
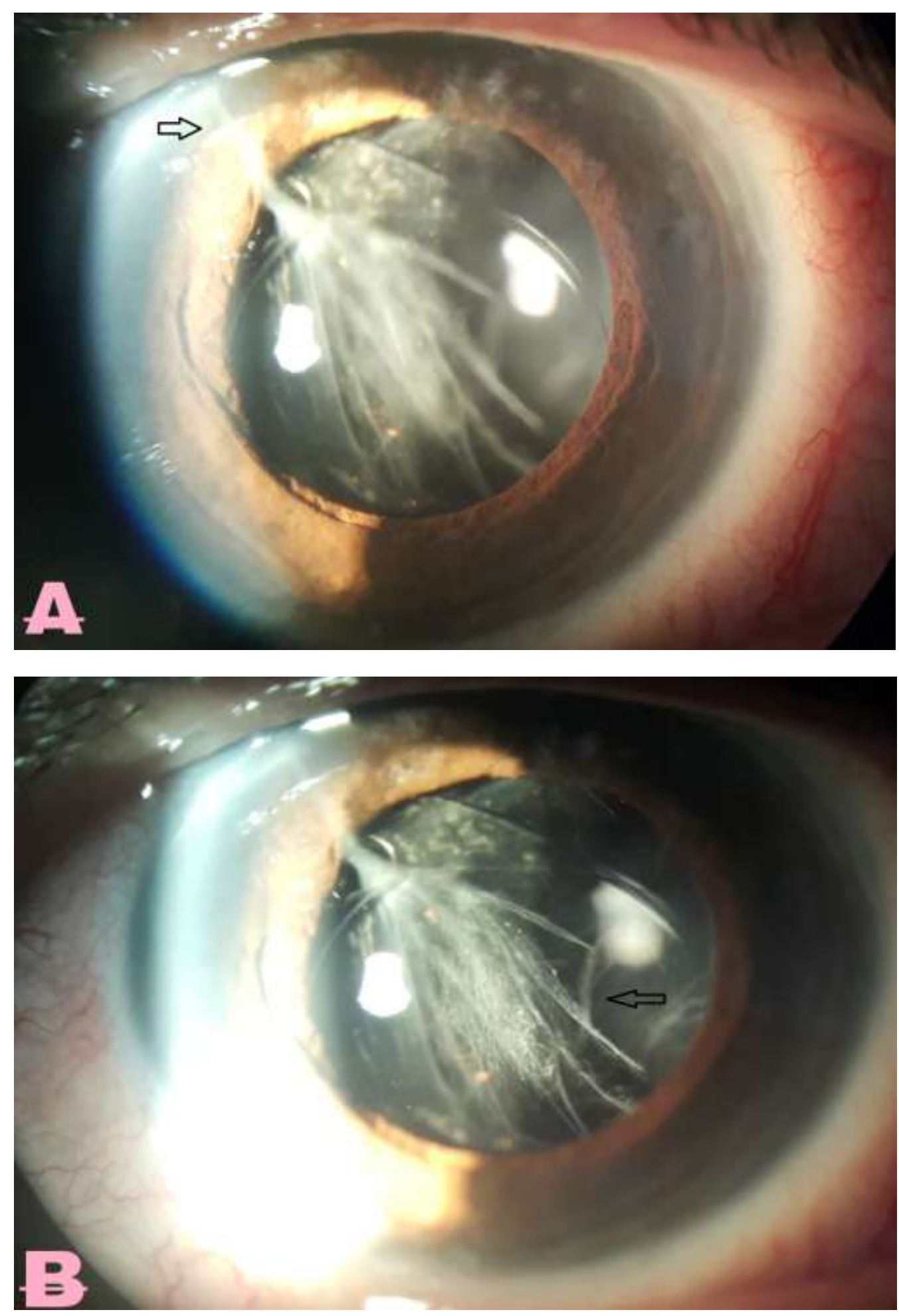


\section{References:-}

1. Jacobs, P. M. (2008). Vitreous loss during cataract surgery: prevention and optimal management. Eye, 22(10), 1286.

2. Ang GS, Whyte IF. Effects and outcomes of posterior capsule rupture in a district general hospital setting. $J$ Cataract Refract Surg 2006; 32: 623-627.

3. Moore JK, Scott IU, Flynn HW, Smiddy WE, Murray TG, Kim JE et al. Retinal detachment in eyes undergoing pars plana vitrectomy for removal of retained lens fragments. Ophthalmology 2003; 110: 709713.

4. Aaberg TM, Rubsamen PE, Flynn HW, Chang S, Mieler WF, Smiddy WE. Giant retinal tear as a complication of attempted removal of intravitreal lens fragments during cataract surgery. Am $J$ Ophthalmol 1997; 124: 222-226. 